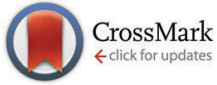

Cite this: Phys. Chem. Chem. Phys., 2015, 17, 23165

Received 21st July 2015,

Accepted 5th August 2015

DOI: $10.1039 / c 5 c p 04255 k$

www.rsc.org/pccp

\title{
Reactive interlayer based ultra-low moisture permeable membranes for organic photovoltaic encapsulation
}

\author{
Sindhu Seethamraju, ${ }^{a}$ Praveen C. Ramamurthy ${ }^{\mathrm{ab}}$ and Giridhar Madras*c \\ Reactive interlayers consisting of zero valent iron and copper nanoparticles have been successfully \\ incorporated into Surlyn films to fabricate moisture barrier materials with reduced water vapor permeabilities. \\ The reactive nanoparticles dispersed in stearic acid were employed as the interlayers due to their ability to \\ react with moisture. The water vapor transmission rates through the fabricated barrier films with reactive iron \\ and copper interlayers decreased by over 4 orders of magnitude when compared to neat Surlyn. The flexibility \\ and transparency of the barrier films have been evaluated by tensile and UV-visible experiments. Moreover, the \\ accelerated aging studies conducted in accordance with the ISOS-III protocol confirmed the increased \\ lifetimes of the organic photovoltaic (OPV) devices encapsulated with these reactive barrier films.
}

\section{Introduction}

Moisture barrier materials are essential for maintaining the quality and lifetime of the packed products in various applications such as food, pharmaceuticals, electronics, photovoltaics, etc. Moisture is a detrimental factor for device performance in organic electronic devices. ${ }^{1}$ When these devices are exposed to a moist environment, absorption and diffusion of moisture into the device results in the oxidation of electrodes and their delamination, change in active layer morphologies and accelerated degradation of device characteristics. Therefore, flexible barrier films with water vapor transmission rates (WVTR) of $10^{-4}$ to $10^{-6} \mathrm{~g} \mathrm{~m}^{-2}$ day ${ }^{-1}$ are necessary for encapsulation of organic electronic devices to maintain $10000 \mathrm{~h}$ of device lifetimes. ${ }^{2}$ This water vapor permeability requirement is six orders lower than that of the commercially available flexible polymer films.

Various barrier architectures have been developed using organic and inorganic components. The use of inorganic oxides, nitrides, carbides as interlayers was explored by various vacuum based atomic deposition methods to improve the water vapor barrier. These materials showed WVTR up to $10^{-3}$ to $10^{-5} \mathrm{~g} \mathrm{~m}^{-2}$ day ${ }^{-1}$, when used in multiple layers. ${ }^{3-8}$ The complications associated with the presence of defect sites/pinholes, affecting WVTR, are inevitable. ${ }^{9-11}$ Various other moisture barrier architectures were developed

\footnotetext{
${ }^{a}$ Centre for Nanoscience and Engineering, Indian Institute of Science, Bangalore, 560012, India

${ }^{b}$ Department of Materials Engineering, Indian Institute of Science, Bangalore, 560012, India

${ }^{c}$ Department of Chemical Engineering, Indian Institute of Science, Bangalore, 560012, India. E-mail: giridhar@chemeng.iisc.ernet.in; Tel: +91-80-22932321
}

using polymers and nanomaterials such as alumina, graphene oxide, cellulose fibers and nanoclays. ${ }^{12-16}$ It is likely that the diffusion of the gas molecules in these composites occurs through a tortuous path due to the physical barrier for permeation. Therefore, in order to improve the scope of such composite materials for barrier applications, we have investigated the possibility of introducing a reactive component in an interlayer to interact with diffusing water molecules resulting in reduced permeation.

Permeation of gases/vapors through polymers occurs by combination of absorption and diffusion processes. Surlyn is a well known moisture barrier with diffusion controlled permeation for water vapor. ${ }^{17}$ Furthermore, due to the properties such as chemical inertness, flexibility, conformability, transparency and tolerability to ultra-violet (UV) radiation, Surlyn has been chosen as the polymer for outer layers. The interlayer comprised of reactive iron and copper nanoparticles dispersed in stearic acid. Zero valent iron and copper have been widely used for waste treatment in remediation of inorganic components and degradation of organic contaminants, ${ }^{18-20}$ in medicine for drug delivery, anti-microbial applications $^{21,22}$ and in electronic applications for printing purposes ${ }^{23}$ due to their reactivity and economic viability. ${ }^{24}$ However, they have not been employed in gas/vapor barrier materials previously. Therefore, the zero valent iron and copper are further explored for enhancing the moisture barrier for OPV device encapsulation in this study.

\section{Experimental section}

\subsection{Chemicals}

Surlyn, a copolymer of ethylene and methacrylic acid (zinc salt $(0.5-5 \mathrm{wt} \%)$ with $9 \mathrm{wt} \%$ methacrylic acid) of density $0.94 \mathrm{~g} \mathrm{~cm}^{-3}$ 
with melt temperature $\sim 89{ }^{\circ} \mathrm{C}$ and melt index $\sim 5.5$, stearic acid, PCBM and PEDOT-PSS were purchased from Sigma Aldrich Ltd (St. Louis, MO). Sodium borohydride $\left(\mathrm{NaBH}_{4}\right)$, dichlorobenzene of $\sim 99.5 \%$ purity, ferric chloride $\left(\mathrm{FeCl}_{3}\right)$ and copper sulphate $\left(\mathrm{CuSO}_{4} \cdot 5 \mathrm{H}_{2} \mathrm{O}\right)$ were obtained from S.D. Fine Chem. (India) and were used without any further purification. Poly(3-hexylthiophene) (P3HT) was obtained from Rieke Metals Inc. (USA). The epoxy resin (Lapox L12) used for sealing in calcium degradation and accelerated aging experiments was purchased from Atul Industries, Ltd (India).

\subsection{Synthesis of iron and copper nanoparticles}

The zero valent iron and copper nanoparticles were produced by using a solution of $0.25 \mathrm{M} \mathrm{NaBH}_{4}$ as a reducing agent and $0.05 \mathrm{M}$ solutions of $\mathrm{FeCl}_{3}$ and $\mathrm{CuSO}_{4} \cdot 5 \mathrm{H}_{2} \mathrm{O}$, respectively. The $\mathrm{NaBH}_{4}$ solution was added drop wise to the individual salt solutions for 15 min under continuous stirring. This resulted in the formation of black precipitates, respectively, which were filtered and dried thoroughly. Thus obtained nanoparticles of iron and copper were handled under dry conditions and stored in a glove box with an inert atmosphere to prevent oxidation. It was observed that the iron nanoparticles were oxidized when exposed to atmosphere resulting in the change of color from black to brown as given in Scheme 1.

\subsection{Synthesis of the reactive composite moisture barrier material}

Surlyn was compressed at $200 \mathrm{~N} \mathrm{~cm}^{-2}$ and $150{ }^{\circ} \mathrm{C}$ to obtain films of thickness $\sim 50 \mu \mathrm{m}$. The use of organic coatings based on stearic acid was studied previously for improving water vapor barrier properties. ${ }^{25}$ Therefore, $\mathrm{Fe}^{0}$ and $\mathrm{Cu}^{0}$ nanoparticles were mixed with stearic acid at $60{ }^{\circ} \mathrm{C}$, separately at five compositions $(5,10,15,20$ and $30 \mathrm{wt} \%)$. These mixtures of stearic acid and nanoparticles were further sonicated for $10 \mathrm{~min}$ at $60{ }^{\circ} \mathrm{C}$. Thus obtained dispersions of various compositions of reactive nanoparticles in stearic acid were melt coated over neat Surlyn films $(\sim 50 \pm 5 \mu \mathrm{m})$ at $75{ }^{\circ} \mathrm{C}$. The thickness of the coating is $\sim 8 \mu \mathrm{m}$. Then the coated Surlyn films were sealed with neat Surlyn films at $90{ }^{\circ} \mathrm{C}$ in order to avoid the direct exposure of

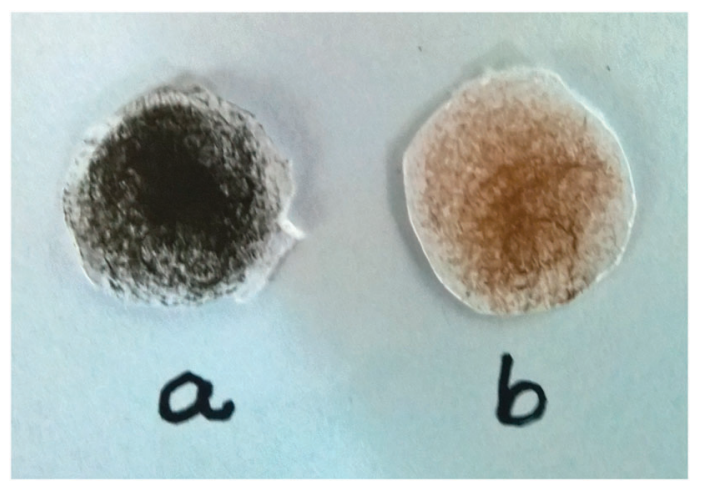

Scheme 1 Photographic image for the zero valent iron nanoparticles changing their color from (a) black to (b) brown after exposure to moisture (images were taken by placing the samples on a white paper).

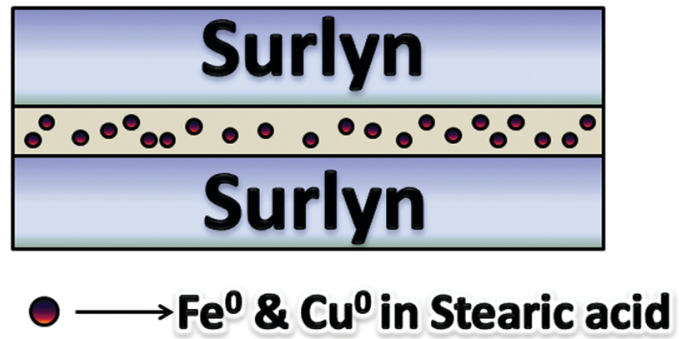

Scheme 2 Barrier architecture for Surlyn/reactive interlayer/Surlyn barrier films.

nanoparticle coatings to the environment. The barrier architecture for the films with interlayer is given in Scheme 2. The barrier films with interlayers containing $\mathrm{Fe}^{0}$ nanoparticles of various compositions $(5,10,15,20,30 \mathrm{wt} \%$ in stearic acid) were designated as F1, F2, F3, F4, F5 and those with interlayers containing $\mathrm{Cu}^{0}$ nanoparticles $(5,10,15,20,30 \mathrm{wt} \%$ in stearic acid) were designated as C1, C2, C3, C4, C5, respectively. Neat Surlyn film was defined as S0. Thus obtained films were used as barrier materials for organic device encapsulation. All the fabrication processes were carried out inside a glove box with an inert atmosphere $\left(\mathrm{H}_{2} \mathrm{O}<5 \mathrm{ppm}\right.$ and $\left.\mathrm{O}_{2}<30 \mathrm{ppm}\right)$ to avoid contamination and oxidation of the nanoparticles.

\subsection{Characterization of $\mathrm{Fe}^{\mathrm{O}}$ and $\mathrm{Cu}^{\mathrm{0}}$ nanoparticles}

The X-ray analyses of the synthesized nanoparticles were conducted on a Rigaku X-ray diffractometer at a scan rate of $2^{\circ} \mathrm{min}^{-1}$. Raman studies were carried out on a LabRAM HR instrument in the range of 100 to $1000 \mathrm{~cm}^{-1}$ operated using $532 \mathrm{~nm}$ excitation laser. A Brookhaven ZetaPALS, zeta potential analyzer was used for determining the particle size in $0.1 \mathrm{mg} \mathrm{mL}^{-1}$ concentrated dispersions of $\mathrm{Fe}^{0}$ and $\mathrm{Cu}^{0}$ nanoparticles by diffuse light scattering (DLS). The fluctuations in the intensity of the scattered light can be related to the varied Brownian diffusion of the particles of different sizes.

\subsection{Characterization of the barrier materials}

Tensile measurements were conducted on a Mecmeisin Micro Universal Testing Machine, with $10 \mathrm{kN}$ load cell at a rate of $25 \mathrm{~mm} \min ^{-1}$ following ASTM D882-12 standard. At least 3 samples were considered for the measurements. The UV-visible transparency of the films was determined using a Perkin Elmer (Lambda-35) UV-visible spectrometer from 230 to $1100 \mathrm{~nm}$ at $1 \mathrm{~nm}$ interval.

2.5.1. Calcium degradation test for the water vapor barrier. The electrical contacts for calcium thin films were taken from the aluminium electrodes, deposited on either side of calcium. Then, the calcium thin film is sealed with the barrier film using an epoxy resin. ${ }^{14}$ The sealed devices were placed in a humid environment (at 95\% $\mathrm{RH}$ and $35{ }^{\circ} \mathrm{C}$ ) and connected to a digital multimeter to continuously monitor the conductance of the calcium thin film. The measured decrease in conductance is directly proportional to the number of oxidized calcium molecules, which can further be correlated with the number of $\mathrm{H}_{2} \mathrm{O}$ 


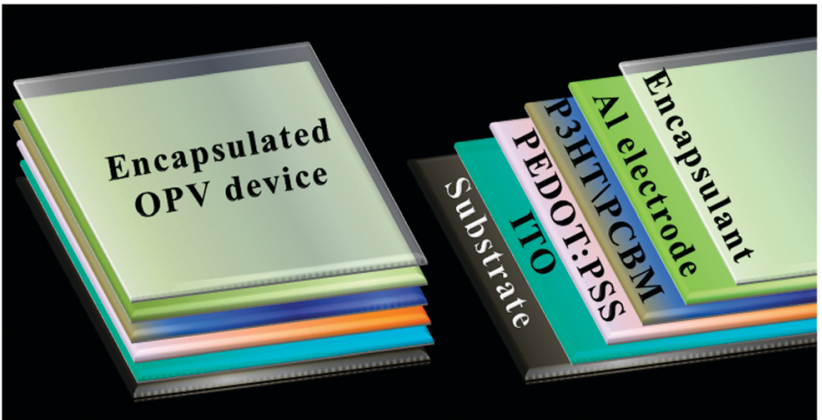

Scheme 3 Schematic for OPV device encapsulation.

molecules reacting with calcium. The number of $\mathrm{H}_{2} \mathrm{O}$ molecules permeating through the film is calculated using eqn (1). The terms $M_{\mathrm{H}_{2} \mathrm{O}}, M_{\mathrm{Ca}}, \partial, \rho, l, b, R$ and $t$ represent the molecular weights of water, calcium molecules, density of calcium, resistivity of calcium, length, width of the calcium thin film, resistance of calcium thin film and time, respectively.

$$
\text { WVTR }=-2 \frac{M_{\mathrm{H}_{2} \mathrm{O}}}{M_{\mathrm{Ca}}} \partial \rho(l / b) \frac{\mathrm{d}(1 / R)}{\mathrm{d} t}
$$

2.5.2. Accelerated aging studies. OPV devices were fabricated inside a glove box under inert conditions. ITO slides were thoroughly cleaned and subjected to ozone treatment prior to the device fabrication. PEDOT-PSS was spin coated (at $1000 \mathrm{rpm}$ ) for $1 \mathrm{~min}$ onto the cleaned ITO coated glass slides and the slides were annealed at $110{ }^{\circ} \mathrm{C}$ for $10 \mathrm{~min} .45 \mathrm{mg}$ of P3HT:PCBM (1.25:1) were dissolved in $1 \mathrm{~mL}$ of dichlorobenzene and was spin coated over the annealed PEDOT-PSS layer. These devices were further annealed at $140{ }^{\circ} \mathrm{C}$ for $10 \mathrm{~min}$. Aluminium electrodes of $\sim 80 \mathrm{~nm}$ were thermally evaporated at $5 \times 10^{-6}$ mbar. Thus fabricated OPVs were sealed with neat Surlyn and the synthesized barrier films with better barrier properties (F4, C4) using an epoxy glue at the edges. The schematic for encapsulated OPV device is given in Scheme 3. The encapsulated devices were then exposed to $85 \% \mathrm{RH}$ and $65{ }^{\circ} \mathrm{C}$ for accelerated weathering studies. The current-voltage $(I-V)$ characteristics for the non-encapsulated and encapsulated OPVs were measured using a 4200 Keithley Semiconductor Characterization System and a Newport Oriel, sol 3A solar simulator. The OPV device efficiencies were averaged for at least 3 devices $(3$ scans per each device) and then normalized with respect to initial efficiency for every encapsulated device. The reduction in the normalized efficiency with time for the OPV devices was further used to evaluate the barrier performance of the encapsulant following eqn (2). The terms $\eta_{0}$ and $\eta_{t}$ correspond to the efficiencies of the OPV device at time $=0$ and $t$, respectively.

$$
\text { Performance of the OPV }(\%)=100 \times \frac{\eta_{0}-\eta_{t}}{\eta_{0}}
$$

\section{Results and discussion}

\section{1. $\mathrm{Fe}^{0}$ and $\mathrm{Cu}^{0}$ nanoparticles}

Zero valent iron $\left(\mathrm{Fe}^{0}\right)$ and copper $\left(\mathrm{Cu}^{0}\right)$ nanoparticles were synthesized by conventional wet chemical synthesis using sodium borohydride by reducing salts of iron and copper, respectively. Thus obtained nanoparticles were characterized for composition and particle size by X-ray diffractometry and diffuse light scattering (DLS) experiments. From Fig. 1(a), the primary peak at $44.7^{\circ}$ corresponds to the 110 plane of bcc structured zero valent iron nanoparticles. The minor peaks at 64.7 and $82.1^{\circ}$ correspond to 200 and 211 planes, respectively. ${ }^{26}$ In the case of $\mathrm{Cu}^{0}$ nanoparticles, the peaks at 43.4, 50.4 and $74.2^{\circ}$ correspond to the 111, 200 and 220 planes of fcc structured particles, respectively. ${ }^{27}$ Furthermore, from the DLS experiments, the $\mathrm{Fe}^{0}$ and $\mathrm{Cu}^{0}$ nanoparticles were found to be $\sim 78$ and $42 \mathrm{~nm}$, respectively. The conductivity values of $\mathrm{Fe}^{0}$ and $\mathrm{Cu}^{0}$ nanoparticles in dispersions were found to be $0.202 \mathrm{mS} \mathrm{cm}^{-1}$ and $0.276 \mathrm{mS} \mathrm{cm}^{-1}$, respectively. Therefore, these results confirm the synthesis of $\mathrm{Fe}^{0}$ and $\mathrm{Cu}^{0}$ nanoparticles.

\subsection{Reactivity of $\mathrm{Fe}^{\mathbf{0}}$ and $\mathrm{Cu}^{0}$ nanoparticles with moisture}

In order to evaluate the reactivity of the synthesized $\mathrm{Fe}^{0}$ and $\mathrm{Cu}^{0}$ nanoparticles, the samples were placed in the humidity chamber under the conditions of WVTR measurement, $95 \% \mathrm{RH}$ and $35{ }^{\circ} \mathrm{C}$ for $24 \mathrm{~h}$. The XRD and Raman studies of these samples are given in Fig. 1(a-d). In Fig. 1(a and b), the marked peaks for the $\mathrm{Fe}^{0}$ and $\mathrm{Cu}^{0}$ nanoparticles exposed to humidity suggest the formation of $\mathrm{FeOOH}$ groups and $\mathrm{Cu}(\mathrm{OH})_{2}$ (with reference to JCPDS No. (35-0505)), ${ }^{28}$ confirming their reactivity. Furthermore, the peaks at 222 and $378 \mathrm{~cm}^{-1}$ for the oxidized $\mathrm{Fe}^{0}$ samples and at 235 and $331 \mathrm{~cm}^{-1}$ for the oxidized $\mathrm{Cu}^{0}$ samples from Raman analysis given in Fig. 1(c and d) are in agreement with the peaks for $\mathrm{FeOOH}^{29}$ and $\mathrm{Cu}-\mathrm{O}$ groups, ${ }^{30}$ respectively. These studies show that the synthesized nanoparticles are capable of reacting with moisture.

\subsection{Mechanical properties of the fabricated barrier films}

The mechanical properties of the films were studied by performing tensile experiments and are given in Fig. 2(a and b). The modulus of elasticity and the elongation at break for the neat Surlyn films were found to be $98( \pm 2) \mathrm{MPa}$ and $138( \pm 5) \%$, respectively. It can be observed that the modulus of elasticity increased and the elongation at break decreased with increasing loading of nanoparticles in the interlayer. The elastic modulus of the barrier films with $\mathrm{Fe}^{0}$ and $\mathrm{Cu}^{0}$ nanoparticles increased to $\sim 145 \mathrm{MPa}$ for $20 \mathrm{wt} \%$ loading. This increase shows the improvement in the stiffness of the flexible Surlyn films with the introduction of reactive interlayers. Therefore, the elongation of the films decreased up to $\sim 40 \%$ for the composite barrier films with the maximum loading of the nanoparticles. However, the films are still flexible enough for OPV encapsulation applications. ${ }^{31}$

\subsection{Transparency of the barrier films with reactive interlayers}

The UV-visible transparent properties of the barrier films are given in Fig. 3(a and b). The visible light transparency of the Surlyn films decreased with the addition of reactive interlayers. Furthermore, it decreased upon increasing the nanoparticle loading in the interlayer. The barrier films with $30 \%$ loadings of nanoparticles (C5 and F5) exhibited the least visible light transparency of $<40 \%$ and therefore, are not suitable for 

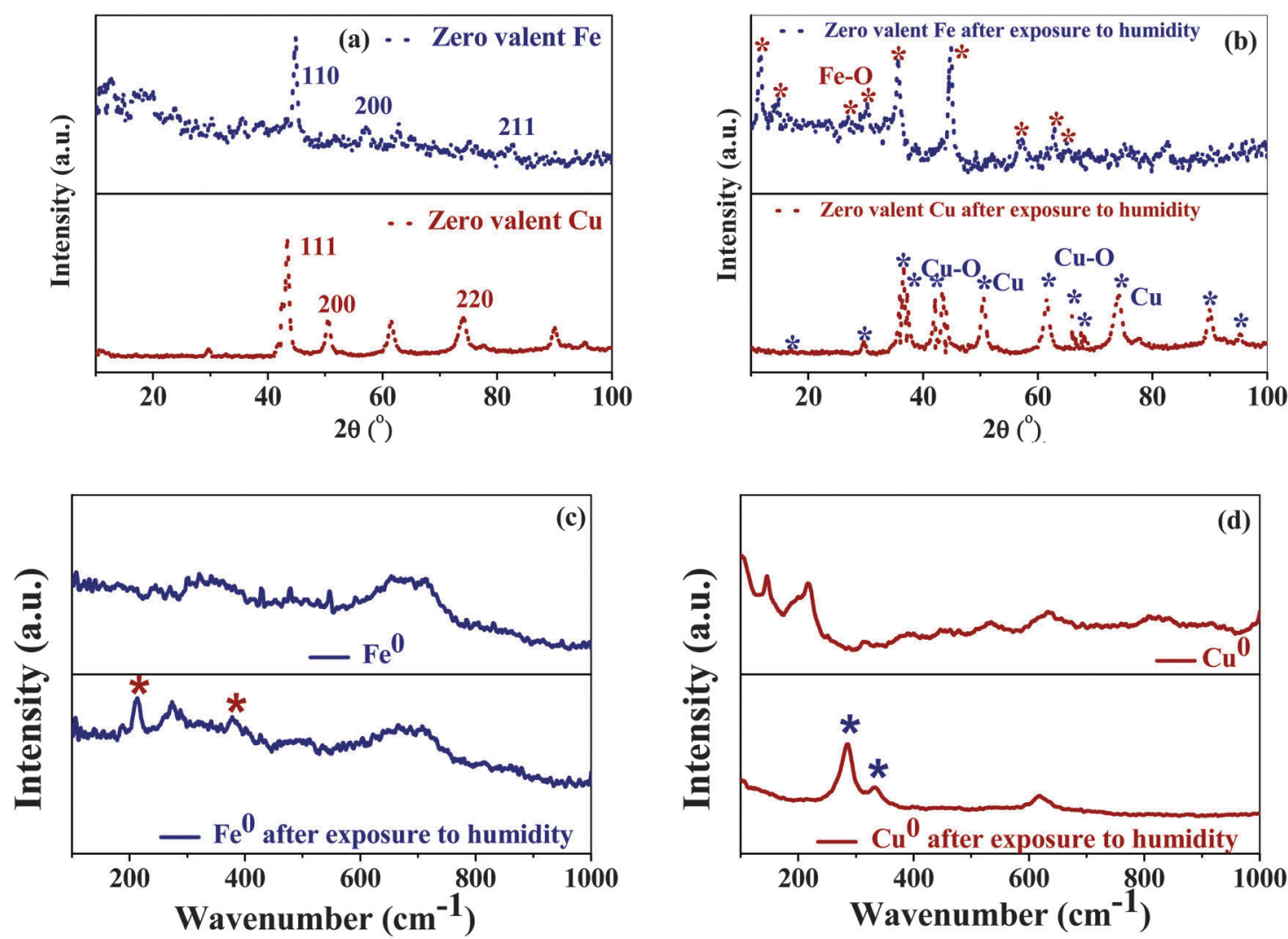

Fig. 1 X-ray diffraction studies for the synthesized bcc and fcc structured $\mathrm{Fe}^{0}$ and $\mathrm{Cu}^{0}$ nanoparticles (a) before, (b) after oxidation, Raman studies for (c) $\mathrm{Fe}^{\mathrm{O}}$ and (d) $\mathrm{Cu}^{0}$ nanoparticles.

encapsulation applications. However, almost all the other composite barrier films (except F4) exhibited a visible light transparency of $>50 \%$ validating their suitability for OPV encapsulation. ${ }^{32}$ Moreover, the light is shined from the substrate side of the device in the encapsulated OPV devices as shown in Scheme 3. Therefore, the transparency of the barrier film will not affect the working of the device. Furthermore, the reduction in transparency of the films to UV light extends the scope for OPV device protection.

\subsection{Water vapor barrier properties of the barrier films with reactive interlayers}

The moisture barrier properties of the barrier films were evaluated using the calcium degradation test method. ${ }^{23}$ In this test, the oxidation of calcium was monitored by the change in conductance of the calcium thin film (of $\sim 210 \mathrm{~nm}, 1 \times 1 \mathrm{~cm}^{2}$ ) deposited on a clean glass slide. ${ }^{33}$ Therefore, in the case of the barrier films with reactive interlayers, the moisture permeating through the barrier film reacts with iron and copper in interlayers resulting in the decrease of WVTR.

The water vapor barrier properties for iron and copper based barrier films are given in Fig. 4(a-d). It can be observed Fig. $4(\mathrm{a}$ and $\mathrm{b})$ that the reduction in conductance is much slower in barrier films with reactive interlayers when compared to the neat Surlyn film from. The calcium test device sealed with a neat Surlyn film degraded completely in $\sim 45 \mathrm{~min}$ while the device sealed with C4 and F4 films took $\sim 5500$ and $6500 \mathrm{~min}$, respectively. It can be observed that the barrier films with a higher concentration of reactive components in the interlayer resulted in longer times for calcium degradation. The WVTR through the neat Surlyn film of $\sim 110 \mu \mathrm{m}$ was found to be $\sim 1.1 \mathrm{~g} \mathrm{~m}^{-2}$ day $^{-1}$. The WVTRs through the fabricated barrier films $(\sim 110 \mu \mathrm{m})$ with iron and copper based reactive interlayers at $500 \mathrm{~min}$ were found to be 12, 6, 1.4, 0.8 and $0.73\left(\times 10^{-3} \mathrm{~g} \mathrm{~m}^{-2} \mathrm{day}^{-1}\right)$ (for F1, F2, F3, F4 and F5) and 11, 2.2, 0.27, 0.14 and $0.11\left(\times 10^{-3} \mathrm{~g} \mathrm{~m}^{-2}\right.$ day $\left.^{-1}\right)$ (for C1, C2, C3, C4 and C5), respectively (Fig. 4(c and d)). From these values, it can be observed that the WVTR decreased by $\sim 2$ orders with the addition of $5 \mathrm{wt} \%$ of reactive iron or copper nanoparticles to the interlayer. Furthermore, the WVTRs decreased up to $\sim 4$ orders for $20 \%$ reactive component in the interlayer for $\mathrm{F} 4$ and $\mathrm{C} 4$ films. These results show that the reactive interlayers are effective in decreasing the WVTRs through the barrier films. It was observed that the WVTRs did not vary significantly from F4 to F5 and C4 to C5. Therefore, 20\% loading of nanoparticles were considered to be optimum for moisture barrier properties. Furthermore, in order to compare the barrier performance of the fabricated reactive materials, eqn (3) is used for studying the enhancement of the water vapor barrier with respect to the neat Surlyn barrier film (Fig. 4(e)).

$$
\text { Barrier enhancement }=\left(\frac{P_{0}}{P}\right)
$$

In eqn (3), $P$ and $P_{0}$ represent the WVTR of the barrier film and neat Surlyn film, respectively. From Fig. 4, it can be observed that the water vapor barrier improved by $\sim 90,180$, 

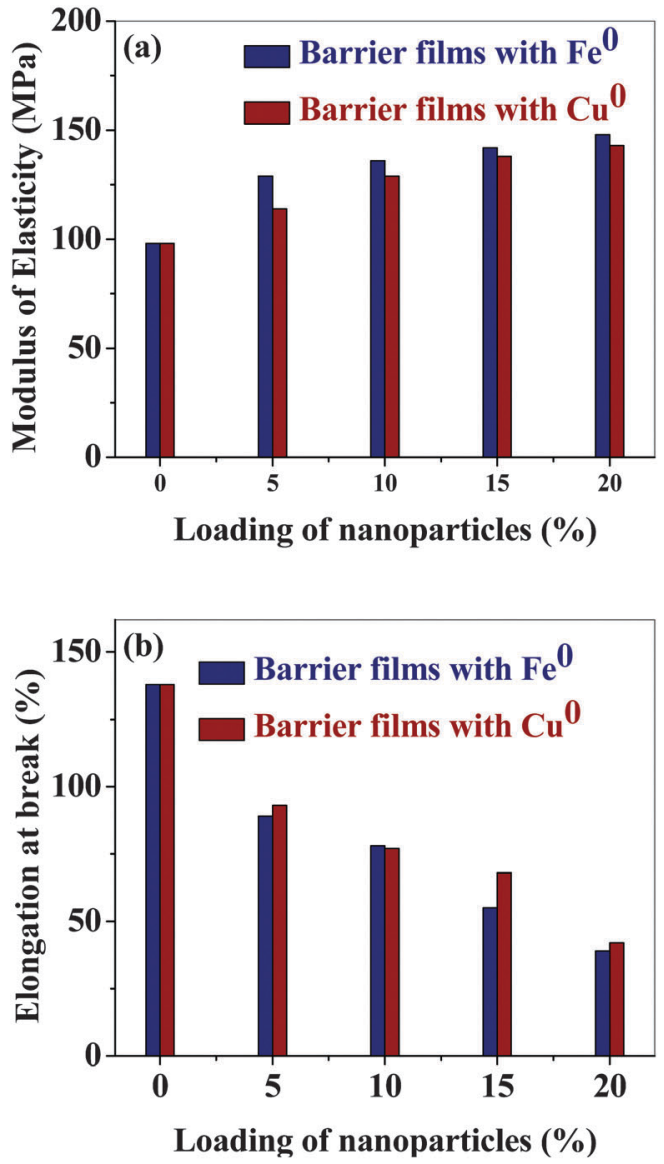

Fig. 2 Mechanical properties of the materials: (a) stiffness of the material determined from the modulus of elasticity and (b) flexibility determined from the elongation at break for the reactive composite barrier films.

785 and 1375 times for F1, F2, F3 and F4 films, while up to 100, 500, 3975 and 7975 times for C1, C2, C3 and C4 films, respectively, with an accuracy of $( \pm 12)$. These results show that the copper based interlayers performed better than the iron based interlayers. Furthermore, the $\mathrm{C} 4$ and F4 films resulted in the maximum enhancement of the water vapor barrier. Therefore, these barrier films were further used for encapsulating OPV devices and conducting accelerated weathering studies.

\subsection{Accelerated aging studies of the encapsulated OPV devices}

These studies were conducted in the dark, at $65{ }^{\circ} \mathrm{C}$ and $85 \% \mathrm{RH}$ following the ISOS-D3 protocol. ${ }^{34}$ The light source intensity was maintained at $1000 \mathrm{~W} \mathrm{~m}^{-2}$. At least three $I-V$ scans in the range of -1 to $1 \mathrm{~V}$ were taken for each device and at least three devices were considered for calculating the average device performance for each composition of the barrier film. The average performances of the unencapsulated and encapsulated OPV devices were determined after exposure to accelerated conditions for $0,10,20,30,90,180,270,360$ and $480 \mathrm{~min}$, respectively (Fig. 5). The device characteristics data for power conversion efficiency (PCE), short circuit current density $\left(I_{\mathrm{SC}}\right)$, open circuit voltage $\left(V_{\mathrm{OC}}\right)$ and fill factor $(\mathrm{FF})$ at initial time, after
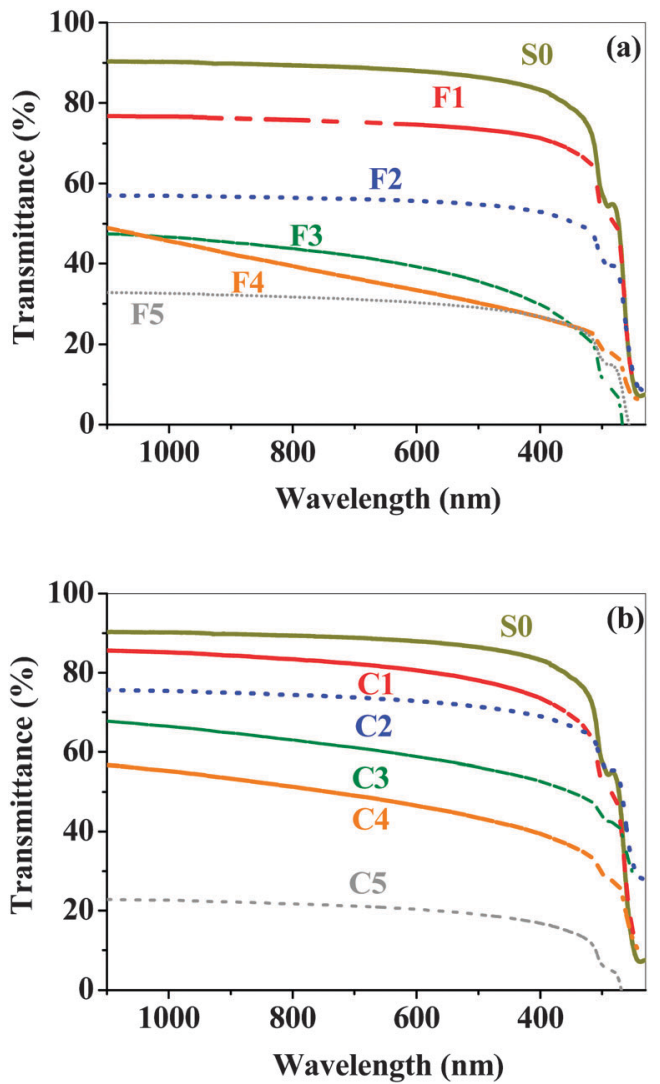

Fig. 3 UV-visible transparency for barrier films with (a) reactive iron and (b) reactive copper nanoparticles.

20 and 480 min of accelerated aging of a representative device among the three devices are given in Table 1 . The time at which the device performance (PCE) drops to half of its initial value, $t_{50}$, is generally considered as the lifetime of the device. The $t_{50}$ for unencapsulated and S0 encapsulated devices were 10 and 25 min, respectively. This shows that the encapsulation of the OPV devices prolongs the lifetime of the device. Moreover, no photovoltaic device performance was observed after $90 \mathrm{~min}$ for these devices. This loss in device performance is mainly due to the exposure of the OPV devices to moisture, which resulted in the drop of fill factor and short circuit current density. Furthermore, the device performance was not recoverable even after soaking in light up to $10 \mathrm{~min}$. This shows the irreversible catastrophic failure ${ }^{35}$ of the devices under accelerated conditions.

The devices encapsulated with reactive barrier films showed much better performance when compared to S0 encapsulated devices by retaining the OPV device performance by $>96 \%$ after $30 \mathrm{~min}$ of accelerated aging. The $t_{80}$ and $t_{50}$ for OPV devices encapsulated with F4 are 230 and $340 \mathrm{~min}$, while for devices encapsulated with $\mathrm{C} 4$, these values are 300 and $480 \mathrm{~min}$, respectively. Furthermore, the device lifetimes under ambient conditions of $25{ }^{\circ} \mathrm{C}$ and $25 \% \mathrm{RH}$ are equivalent to 1024 times the lifetimes under accelerated aging conditions of $65{ }^{\circ} \mathrm{C}$ and $85 \% \mathrm{RH}^{32,36}$ These values clearly indicate that the reactive interlayers are capable of extending the OPV device lifetimes up 

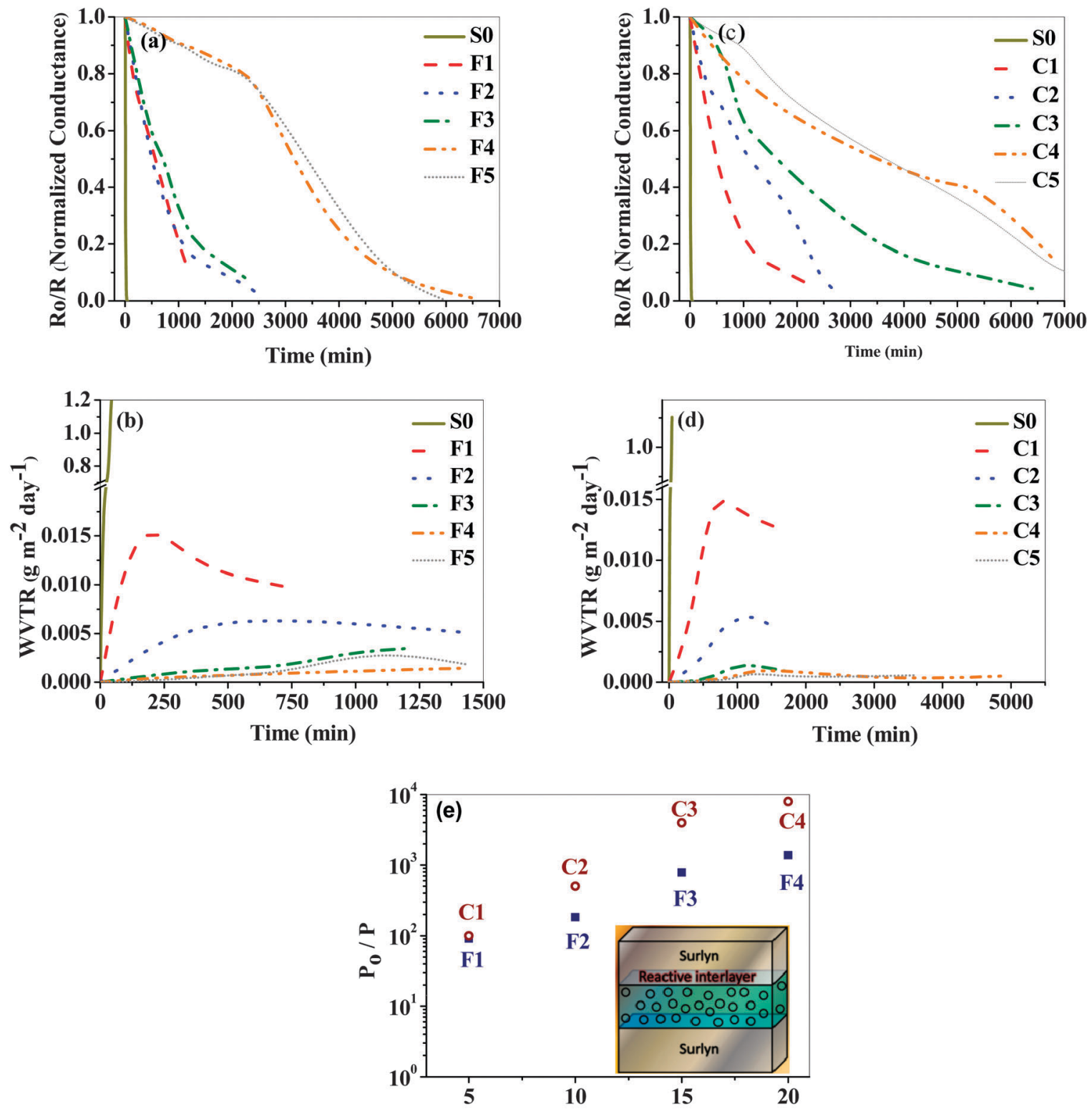

Nanoparticle composition in interlayer (wt. \%)

Fig. 4 Normalized conductance and WVTR for barrier films with reactive ( $a$ and c) iron and (b and d) copper nanoparticles in stearic acid interlayers from calcium degradation test, (e) evaluation of the barrier performance (inset: schematic for the fabricated barrier films with reactive interlayers).

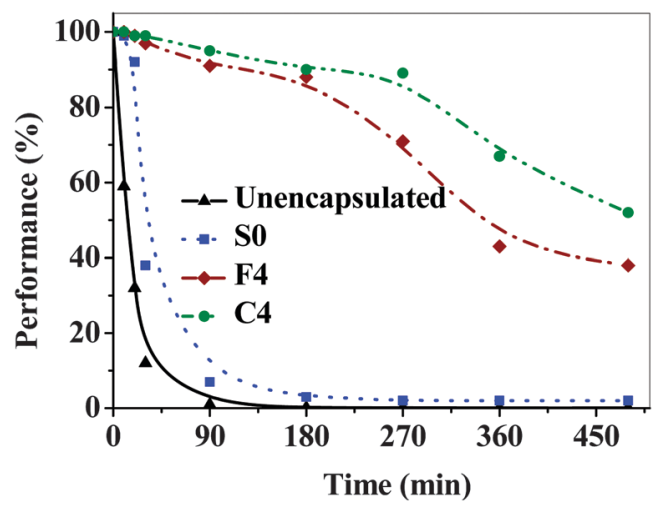

Fig. 5 Accelerated aging studies for encapsulated devices with neat Surlyn and reactive barrier films. to $490000 \min$ ( $\sim 340$ days). Furthermore, it shows that the copper based interlayers are effective as moisture reactive barriers when compared to iron based interlayers as observed from WVTR studies.

\section{Conclusions}

In the case of traditional organic/inorganic coatings, the inorganic component basically acts as a diffusion barrier. The approach of reactive interlayers has been employed in this work, which is simple, scalable and reliable for the development of better water vapor barrier materials. Furthermore, the purpose of introducing reactive interlayers is to increase the 
Table 1 Device characteristics for unencapsulated and encapsulated OPV devices before and after accelerated aging

\begin{tabular}{|c|c|c|c|c|c|c|c|c|c|c|c|c|}
\hline$\frac{\text { Device }}{\text { Time (min) }}$ & \multicolumn{3}{|c|}{$\operatorname{PCE}(\eta$ in \%) } & \multicolumn{3}{|c|}{$V_{\mathrm{OC}}(\mathrm{V})$} & \multicolumn{3}{|c|}{$I_{\mathrm{SC}}\left(\mathrm{mA} \mathrm{cm} \mathrm{cm}^{-2}\right)$} & \multicolumn{3}{|c|}{$\mathrm{FF}(\%)$} \\
\hline Unencap. & 3.1 & 0.74 & 0.015 & 0.6 & 0.58 & 0.49 & 10.6 & 2.9 & 0.01 & 49.7 & 43.2 & 0.74 \\
\hline F4 & 2.7 & 2.64 & 1.09 & 0.58 & 0.58 & 0.57 & 9.9 & 9.9 & 4.6 & 48.6 & 45 & 43.8 \\
\hline $\mathrm{C} 4$ & 2.8 & 2.68 & 1.42 & 0.59 & 0.59 & 0.57 & 10.3 & 10.2 & 5.2 & 51 & 47.8 & 46.3 \\
\hline
\end{tabular}

diffusion path and to trap the permeating water molecules by reacting with them. Therefore, the synthesized moisture barrier materials proved to be better than the previously studied reactive nanocomposite encapsulants, which exhibited WVTR $\sim 8 \times 10^{-3} \mathrm{~g} \mathrm{~m}^{-2} \mathrm{day}^{-1}$. $^{37}$ The use of two metallic nanoparticles $\left(\mathrm{Fe}^{0}\right.$ and $\left.\mathrm{Cu}^{0}\right)$ in the design of reactive moisture barrier materials was studied by calcium degradation experiments. A drastic reduction in WVTRs by two orders was observed with the addition of $5 \%$ reactive iron or copper nanoparticles. Further addition of the copper nanoparticles up to $20 \%$ resulted in 4 order reduction in WVTR $\left(\sim 1.4 \times 10^{-4} \mathrm{~g} \mathrm{~m}^{-2}\right.$ day $\left.^{-1}\right)$, when compared to the neat Surlyn. These materials were flexible and transparent in the visible light region. In order to evaluate the barrier material as an OPV encapsulant, the encapsulated OPV devices were subjected to accelerated aging tests. The OPV device encapsulated with $\mathrm{C} 4$ showed the best performance by retaining $\sim 50 \%$ of its initial performance even after $480 \mathrm{~min}$ of accelerated aging. It was also observed that copper nanoparticles resulted in better reactive interlayers than iron nanoparticles from both WVTR and OPV aging studies. However, this study on introducing the reactive interlayer indicates the effectiveness of the reactive, passivating interlayer in between flexible polymer layers as an ultra-high water vapor barrier material.

The current state-of-art barrier materials for organic device encapsulation are based on nanomaterials such as silica, alumina, $\mathrm{ZnO}$ and clays in various polymers. ${ }^{38-42}$ However, these materials exhibit WVTR in the range of $10^{-3}$ to $10^{-4} \mathrm{~g} \mathrm{~m}^{-2}$ day $^{-1}$, which is slightly lower than that observed in this study. These materials, therefore, do not suffice the barrier requirements posed by organic electronics. However, the current investigation on reactive composites provides a possibility of improving the moisture barrier with the introduction of reactive nano-components. Therefore, future work on improving the water vapor barrier properties can investigate new Ti and $\mathrm{Al}$ based nanomaterials with crosslinked polymers, ${ }^{43-45}$ stacking of interlayers containing the reactive nanomaterials and combinations of different nanomaterials in the interlayers.

\section{Acknowledgements}

The authors would like to acknowledge the financial support for this project from SERB, Department of Science and Technology (1362/2014) and IUSSTF/JCERDC-SERIIUS/2012 dated 22nd Nov. 2012. The corresponding author thanks Department of Science and Technology, India for the J. C. Bose fellowship.

\section{Notes and references}

1 L. Ciammaruchi, A. D. Carlo and C. W. Tang, Symposium FF The Grand Challenges in Organic Electronics, 2014, vol. 1695.

2 G. Dennler, C. Lungenschmied, H. Neugebauer, N. S. Sariciftci, M. Latrèche, G. Czeremuszkin and M. R. Wertheimer, Thin Solid Films, 2006, 511-512, 349-353.

3 A. A. Dameron, S. D. Davidson, B. B. Burton, P. F. Carcia, R. S. McLean and S. M. George, J. Phys. Chem. C, 2008, 112, 4573-4580.

4 P. F. Carcia, R. S. McLean, M. H. Reilly, M. D. Groner and S. M. George, Appl. Phys. Lett., 2006, 89, 031915.

5 E. Langereis, M. Creatore, S. B. S. Heil, M. C. M. van de Sanden and W. M. M. Kessels, Appl. Phys. Lett., 2006, 89, 081915.

6 J. Granstrom, M. Villet, T. Chatterjee, J. A. Gerbec, E. Jerkunica and A. Roy, Appl. Phys. Lett., 2009, 95, 093306.

7 W. M. Yun, J. Jang, S. Nam, L. H. Kim, S. J. Seo and C. E. Park, ACS Appl. Mater. Interfaces, 2012, 4, 3247-3253.

8 J. Meyer, P. Görrn, F. Bertram, S. Hamwi, T. Winkler, H.-H. Johannes, T. Weimann, P. Hinze, T. Riedl and W. Kowalsky, Adv. Mater., 2009, 21, 1845-1849.

9 A. S. da Silva Sobrinho, G. Czeremuszkin, M. Latrèche and M. R. Wertheimer, J. Vac. Sci. Technol., A, 2000, 18, 149-157.

10 G. Czeremuszkin, M. Latrèche, M. R. Wertheimer and A. S. da Silva Sobrinho, Plasmas Polym., 2001, 6, 107-120.

11 A. S. da Silva Sobrinho, G. Czeremuszkin, M. Latrèche and M. R. Wertheimer, Surf. Coat. Technol., 1999, 116-119, 1204.

12 I.-H. Tseng, M.-H. Tsai and C.-W. Chung, ACS Appl. Mater. Interfaces, 2014, 6, 13098-13105.

13 T. T. T. Ho, T. Zimmermann, S. Ohr and W. R. Caseri, ACS Appl. Mater. Interfaces, 2012, 4, 4832-4840.

14 E.-H. Song, B.-H. Kang, T.-Y. Kim, H.-J. Lee, Y.-W. Park, Y.-C. Kim and B.-K. Ju, ACS Appl. Mater. Interfaces, 2015, 7, 4778-4783.

15 S. Seethamraju, P. C. Ramamurthy and G. Madras, ACS Appl. Mater. Interfaces, 2013, 5, 4409-4416.

16 Y. H. Yang, L. Bolling, M. A. Priolo and J. C. Grunlan, Adv. Mater., 2013, 25, 503.

17 S. Seethamraju, P. C. Ramamurthy and G. Madras, RSC Adv., 2014, 4, 11176-11187.

18 B. I. Kharisov, O. V. Kharissova and H. V. R. Dias, Nanomaterials for Environmental Protection, Wiley, 2014.

19 S. Li, W. Wang, W. Yan and W. Zhang, Environ. Sci.: Processes Impacts, 2014, 16, 524-533.

20 G. Wen, S.-J. Wang, J. Ma, T.-L. Huang, Z.-Q. Liu, L. Zhao and J.-L. Xu, J. Hazard. Mater., 2014, 275, 193-199. 
21 F. Rispoli, A. Angelov, D. Badia, A. Kumar, S. Seal and V. Shah, J. Hazard. Mater., 2010, 180, 212-216.

22 K. Simeonidis, C. Martinez-Boubeta, L. Balcells, C. Monty, G. Stavropoulos, M. Mitrakas, A. Matsakidou, G. Vourlias and M. Angelakeris, J. Appl. Phys., 2013, 114, 103904.

23 S. Kubota, T. Morioka, M. Takesue, H. Hayashi, M. Watanabe and R. L. Smith Jr., J. Supercrit. Fluids, 2014, 86, 33-40.

24 J. Filip, F. Karlický, Z. Marušák, P. Lazar, M. Černík, M. Otyepka and R. Zbořil, J. Phys. Chem. C, 2014, 118, 13817-13825.

25 S. Seethamraju, P. C. Ramamurthy and G. Madras, Appl. Phys. Lett., 2014, 105, 104102.

26 Y.-P. Sun, X. Li, J. Cao, W. Zhang and H. P. Wang, Adv. Colloid Interface Sci., 2006, 120, 47-56.

27 C.-C. Huang, S.-L. Lo and H.-L. Lien, Chem. Eng. J., 2012, 203, 95-100.

28 S. H. Joo and F. Cheng, Nanotechnology for Environmental Remediation, Springer, New York, 2006.

29 M. K. Nieuwoudt, J. D. Comins and I. Cukrowsk, J. Raman Spectrosc., 2011, 42, 1335-1339.

30 H. F. Goldstein, D. S. Kim, P. Y. Yu and L. C. Bourne, Phys. Rev. B: Condens. Matter Mater. Phys., 1990, 41, 7192-7194.

31 S. Savagatrup, A. D. Printz, T. F. O'Connor, A. V. Zaretski and D. J. Lipomi, Chem. Mater., 2014, 26, 3028-3041.

32 K. R. McIntosh, J. N. Cotsell, J. S. Cumpston, A. W. Norris, N. E. Powell and B. M. Ketola, Photovoltaic Specialists Conference, 34th IEEE, 2009.

33 R. Paetzold, A. Winnacker, D. Henseler, V. Cesari and K. Heuser, Rev. Sci. Instrum., 2003, 74, 5147-5150.

34 M. O. Reese, S. A. Gevorgyan, M. Jørgensen, E. Bundgaard, S. R. Kurtz, D. S. Ginley, D. C. Olson, M. T. Lloyd, P. Morvillo, E. A. Katz, A. Elschner, O. Haillant, T. R. Currier, V. Shrotriya, M. Hermenau, M. Riede, K. R. Kirov, G. Trimmel, T. Rath, O. Inganäs, F. Zhang,
M. Andersson, K. Tvingstedt, M. Lira-Cantu, D. Laird, C. McGuiness, S. (Jimmy) Gowrisanker, M. Pannone, M. Xiao, J. Hauch, R. Steim, D. M. DeLongchamp, R. Rösch, H. Hoppe, N. Espinosa, A. Urbina, G. YamanUzunoglu, J.-B. Bonekamp, A. J. J. M. van Breemen, C. Girotto, E. Voroshazi and F. C. Krebs, Sol. Energy Mater. Sol. Cells, 2011, 95, 1253-1267.

35 S. A. Gevorgyan, M. Corazza, M. V. Madsen, G. Bardizza, A. Pozza, H. Müllejans, J. C. Blakesley, G. F. A. Dibb, F. A. Castro, J. F. Trigo, C. M. Guillén, J. R. Herrero, P. Morvillo, M. G. Maglione, C. Minarini, F. Roca, S. Cros, C. Seraine, C. H. Law, P. S. Tuladhar, J. R. Durrant and F. C. Krebs, Polym. Degrad. Stab., 2014, 109, 162-170.

36 S. Schuller, P. Schilinsky, J. Hauch and C. J. Brabec, Appl. Phys. A: Mater. Sci. Process., 2004, 79, 37-40.

37 G. N. Kopanati, S. Seethamraju, P. Ramamurthy and G. Madras, RSC Adv., 2015, 32580-32587.

38 J. Gaume, C. Taviot-Gueho, S. Cros, A. Rivaton, S. Thérias and J.-L. Gardette, Sol. Energy Mater. Sol. Cells, 2012, 99, 240-249.

39 S. Saravanan, S. Gupta, P. C. Ramamurthy and G. Madras, Polym. Compos., 2014, 35, 1426-1435.

40 S. Gupta, S. Seethamraju, P. C. Ramamurthy and G. Madras, Ind. Eng. Chem. Res., 2013, 52, 4383-4394.

41 S. Saravanan, P. C. Ramamurthy and G. Madras, Composites, Part B, 2015, 73, 1-9.

42 E.-H. Song, B.-H. Kang, T.-Y. Kim, H.-J. Lee, Y.-W. Park, Y.-C. Kim and B.-K. Ju, ACS Appl. Mater. Interfaces, 2015, 7, 4778-4783.

43 S. G. Roy, K. Bauri, S. Pal, A. Goswami, G. Madras and P. De, Polym. Int., 2012, 62, 463-473.

44 V. Subramanian, J. Choi, E. Seebauer and R. Masel, Catal. Lett., 2007, 113, 13-18.

45 S. G. Roy, K. Bauri, S. Pal and P. De, Polym. Chem., 2014, 5, 3624-3633. 